\title{
0 projeto de mulheres arquitetas na Revista Projeto nos anos 1980
}

\author{
Submetido em: 28/10/2019, aprovado em: 17/12/2019 10.30612/mvt.v7i13.10593 \\ Maria Luiza Pereira' \\ Kelly Cristina Magalhães ${ }^{2}$
}

RESUMO: As relaçôes de gênero não se configuram como categoria reconhecida e dotada de credibilidade na análise de projeto de arquitetura em âmbito nacional na pesquisa acadêmica. Por essa razão, parte da problemática, à qual este projeto se dedica, refere-se ao papel da prática literária e projetual e seus instrumentos na construção do conhecimento acadêmico. Nos dedicamos a sistematizar e analisar projetos publicados na década de 1980, identificando sua história a partir da perspectiva de gênero e procurando entender quais as suas conexóes com a escassez de referências femininas dentro do meio acadêmico. A pesquisa em questão se vale da revisão bibliográfica em clássicos da história do projeto e investigação histórica em fontes primárias de relação da arquitetura com o público. Esta, por sua vez, revela temáticas postas à margem pela sociedade, como por exemplo, a igualdade de gênero relacionada diretamente ao ensino logo, ao projeto. Assim, o propósito é evidenciar a necessidade do estudo de gênero no ensino de arquitetura e, consequentemente, formular diretrizes que gerem debate, açôes e articulaçôes dentro da universidade sobre a validade do projeto arquitetônico feito por mulheres na construção do conhecimento acadêmico.

Palavras-chave: Mulher. História. Arquitetura.

\section{Archtect women}

ABSTRACT: Gender relations do not constitute a recognized and credible category in the analysis of architecture projects at the national level in academic research. Accordingly, part of the issue to which this project is committed to is the role of literary and design practice and its instruments in the construction of academic knowledge. Therefore, this work dedicates to systematizing and analyzing published projects in the 1980s, identifying their narrative from a gender perspective and attempting to comprehend their relationship with female references deficiency within academia.

\footnotetext{
1 Estudante de Arquitetura e Urbanismo na Faculdade de Arquitetura da Universidade Estadual Paulista - Júlio de Mesquita Filho de Bauru (2020), pereira.mrlz@gmail.com.

2 Possui graduaçáo em Arquitetura e Urbanismo pelo Centro Universitário Moura Lacerda (1997), mestrado em Engenharia Urbana pela Universidade Federal de São Carlos (2002) e doutorado em Engenharia Urbana pela Universidade Federal de São Carlos (2016). Atualmente é professora da Universidade Estadual Paulista - Júlio de Mesquita Filho e da FIB- Faculdades Integradas de Bauru. Tem experiência na área de Arquitetura e Urbanismo, com ênfase em História do Urbanismo, atuando principalmente nos seguintes temas: planejamento urbano, políticas públicas, planejamento paisagístico, ferrovia e patrimônio histórico, kelly@faac.unesp.br
} 
The research is based on the bibliographical revision of the history of project masterworks and on the historical investigation in primary sources of architecture's relationship with the public. As a result, issues set aside by society are revealed, such as gender equality being directly related to education, thus, to the project. In brief, the purpose is to highlight the demand for gender studies in architecture teaching and, consequently, to formulate guidelines that generate debate, actions, and articulations within the university about the validity of the architectural project made by women in the construction of academic knowledge.

Keywords: Woman. History. Archtecture.

\section{Mujeres arquitectas}

RESUMEN: Las relaciones de género no constituyen una categoría reconocida y en el análisis de proyectos arquitectónicos a nivel nacional en investigación académica. Por lo tanto, parte del problema al que este proyecto se dedica, se refiere a la función de la literatura y del proyecto y sus herramientas en la construccion del conocimiento académico. Nos dedicamos a reglar y analizar los proyectos publicados en la década de 1980, estableciendo su historia desde una faceta de género y buscando comprender cuales sus conexiones con la escasez de referenciales femeninos dentro del medio académico.

Esta investigación emplea la revisión bibliográfica de clásicos literarios de la historia del proyecto y la búsqueda histórica en raíces primarias de la relación entre la arquitectura y el público. Se comprende que el estudio señalará temáticas desvalidas por la sociedad, como por ejemplo la igualdad de género relacionada directamente a la carrera, por ello, al proyecto. Así pues, el objetivo final es que esta investigación establezca la necesidad de los estudios de género en la carrera de arquitectura, habiendo como motivación las normas que generen discusiones, acciones y articulaciones dentro de la universidad a cerca de la validad del proyecto arquitectónico hecho por mujeres em la construccion del conocimiento académico.

Palavras Clave: Mujer. Historia. Arquitectura.

\section{INTRODUÇÃO}

A pesquisa consiste em analisar a trajetória projetual da mulher arquiteta na década de 1980 na Revista Projeto, a partir da perspectiva de gênero e feminismo. Para tanto, o trabalho está estruturado em quatro eixos de pesquisa que tem o objetivo de, quando juntos, possibilitar o reconhecimento, identificação e valorização da contribuição das mulheres para a arquitetura. Caracteriza-se o tema como essencial para o ensino atual, visto o número crescente de profissionais no mercado e ingressas nas universidades brasileiras ao longo da segunda metade do século XX. Este estudo evidencia a necessidade da reeducação a partir de novas demandas do ensino.

Em primeiro instante, com base bibliográfica histórica, o cenário brasileiro é reconhecido como contexto para temas como cultura, política, gênero e representatividade. Atrelados diretamente à luta da mulher pós Segunda Guerra Mundial, os termos trouxeram pensamentos de teóricos como 
CHAUÍ (1980), MUXÍ; MONTANER (2014), RIBEIRO (2017) e RAGO (1985) com o objetivo de destacar a importância do discurso no ensino.

Em segundo instante, é feita a avaliação de bibliografias clássicas de historiadores como FRAMPTON (2008), ARGAN (1984), MONTANER (1993) e BENÉVOLO (2006). A partir da pesquisa bibliográfica e adotado o pressuposto que a disciplina de história compóe a base referencial do profissional de arquitetura, os quatro autores que discorrem sobre História e Teoria da Arquitetura, são analisados através da metodologia desenvolvida por LIMA (2004) que, por sua vez, discorre sobre a existência de "modelos linguísticos masculinos" e "mecanismos de dominação simbólica” pelos quais, sutilmente, acontece o fenômeno de perpetuação da superioridade masculina indicada pelo olhar dominante (BOURDIEU, 2003).

Como terceiro instante de pesquisa, analisa-se o contexto histórico que apresenta a relação feminismo e arquitetura, mostrando a possibilidade de investigar como teóricas da atualidade enfrentam o assunto de gênero na área, sob a perspectiva de inserção do tema dentro da educação. Por intermédio da produção de história de arquitetas, ou seja, através da contribuição de um grupo "marginal" da sociedade, entende-se como a história possui diversos pontos de vista e, portanto, diversas maneiras de serem repassadas. Logo, é abordada a construção da história da arquitetura tradicional e a atual urgência sobre uma perspectiva de pesquisa crítica e feminista da história, ensinada a jovens arquitetas e arquitetos a partir da visão de WAISSMAN (1990), LIMA (2014) e BASTOS; ZEIN (2010).

Comprovada a influência e responsabilidade da literatura especializada como meio de comunicação para profissionais, a revista, por sua periodicidade, mostra-se a forma que mais abrange pessoas envolvidas com arquitetura. Tendo como cenário contextual a década de 1980, a investigação documental no periódico Projeto se justifica pelo nascimento e desenvolvimento da crítica arquitetônica nacional como reflexo a um período de surgimento de diversos ideários originários da década anterior e, especialmente, uma resposta à redemocratização da mais longa ditadura da América Latina.

Priorizando o contexto de inserção e as variáveis a ele inerentes, o objetivo é essencialmente identificar o corpo editorial da revista e a seleção de projetos de mulheres arquitetas. Como base referencial inicial, foram utilizados os trabalhos analíticos e críticos sobre projetos de autoria feminina produzidos na matéria de História da Arquitetura IV, da Faculdade de Arquitetura e Urbanismo da UNESP - Bauru, ministrada em 2018 pela Professora Doutora Kelly Magalhães. A temática mostra mais uma vez sua importância a partir do momento em que a disciplina teve essa tônica por demanda dos alunos.

A visibilidade da revista por profissionais, somada à trabalhos produzidos durante o estudo da disciplina, permite o questionamento sobre a atuação de mulheres, tanto produzindo o conteúdo da revista quanto sendo selecionadas por seus projetos. Por meio da análise geral e análise de discurso, é possível observar resultados quantitativos e qualitativos sobre as publicaçóes, bem como apresentar análise crítica sobre o modo como mulheres foram representadas através desse meio de comunicação específico.

Como consequência, os casos analisados formam um acervo de informaçôes sobre arquiteta e sua produçáo, nunca desvinculando o contexto das criaçóes. Através do estudo de dezesseis revistas, e fichamentos, o quadro profissional de arquitetas como Odiléia Toscano, Marília Sant'anna de 
Almeida e Cátia Avellar são revelados, mostrando que ser mulher e, portanto, carregar o olhar marginal, influencia no conhecimento técnico.

\section{FUNDAMENTAÇÃO TEÓRICA}

Fenômeno de transformação, a arquitetura como um elemento essencialmente cultural, pode ser definido como um tipo de materialização das ideias advindas do trabalho dos indivíduos de uma sociedade civil. Por sua vez, qualquer produto cultural surge a partir de uma ideologia pré-estabelecida, sendo ideologia aqui definida a partir do pensamento marxista, ou seja, um processo pelo qual as ideias da classe dominante se desvincula da práxis - representada pelo trabalhador e/ ou classe dominada - e se torna a ideia de todas as classes, uma ideia dominante (CHAUÍ,1980). Diferentemente de ideário - definido pelo "conjunto sistemático encadeado de ideias" (CHAUÍ, 1980, p.07) - a ideologia é compulsoriamente interiorizada por cada indivíduo da sociedade através da massificação de uma cultura universal produzida por "homens, brancos, heteronormativos, colonizadores" e tem relação intrínseca com o poder político, econômico e o censo coletivo de grupo (MUXÍ; MONTANER, 2014).

Por sua vez, a política é a forma pela qual a sociedade civil se organiza e estabelece "critérios da justiça e do bom governo" e, assim, propóe condiçóes em que o homem possa "atingir a felicidade (o bem-estar) na sociedade, em sua existência coletiva” (JAPIASSÚ; MARCONDES, 2001, p.152). De natureza normativa e regida pela ideologia dominante, a política possui relação de espaço/ tempo com a arquitetura, inspirando-a e instigando-a. Essa relação da realidade histórico-social e a materialização de ideias - representada pela arquitetura como um produto cultural - permite afirmar que existe uma dialética entre os planos, concluindo que não há arquitetura que não seja política e não há arquitetura sem que haja reflexão (mesmo que não percebida) sobre seu contexto histórico.

No entanto, há certa deturpação e invisibilidade dessa conexão na sociedade pós-colonialista em que muitos países, incluindo o Brasil, se enquadram. O modelo civilizatório, onde o ideal é ditado pelo grupo social, econômico e politicamente dominante e onde as diferenças são homogeneizadas por uma cultura universal, tende a suprimir e controlar a representatividade e ideários daqueles que são historicamente oprimidos pela raça, classe e/ou gênero. De acordo com Lélia Gonzales (RIBEIRO, 2019), a linguagem é o principal mecanismo de manutenção de poder:

Quem possui o privilégio social, possui o privilégio epistêmico, uma vez que o modelo valorizado e universal é o branco. A consequência dessa hierarquizaçáo legitimou como superior a explicação epistemológica eurocêntrica conferindo ao pensamento moderno ocidental a exclusividade do que seria conhecimento válido, estruturando-o como dominante e assim inviabilizando outras experiências do conhecimento. GONZALES (2019, p. 25, apud RIBEIRO, 2019, n.p)

Sabe-se que "mulher" é definido como o "ser individual", representa a experiência exclusiva de uma pessoa do sexo feminino. As mulheres, como mostram dados do IBGE (2018), tem menores rendimentos salariais, são menos representadas politicamente e, em cargos gerenciais, são em menor quantidade (IBGE, 2018, p.1). Logo, infere-se que a "mulher", em sua pluralidade e através de diferentes formas de opressão, é um ser marginal, rejeitada pela sociedade "padrão". O grupo, compreendido por homens brancos que, além de universalizarem e generalizarem experiências 
individuais, invisibilizam grupos marginais através da história, contando-a através do "privilégio epistemológico" que lhe é concedido intrinsicamente.

Margareth Rago (1985) compreende a universalização no século XIX quando, através das ações higienistas, "convivemos com o desejo de eliminar diferenças" (RAGO, 1985, p.). Particularmente sobre gênero, Rago (1985) descreve o modelo de família nuclear, centralizada na mulher e simbolizada pela mãe-sacrifício/esposa perfeita, como resultado de uma construçáo social que dura anos e implica até hoje na desvalorização profissional, política, intelectual e moral da mulher. Segundo RIBEIRO (2019, n.p), "A tomada de consciência sobre o que significa desestabilizar a norma hegemônica é vista como inapropriada ou agressiva, porque aí se está confrontando poder." Portanto, entender mais precisamente como vem sendo construída a imagem da mulher como agente de resistência em lutas sociais e políticas e, como o movimento feminista transforma historicamente a relação de gênero, significa desvendar a história pouco contada sobre um grupo marginal emergente.

Atualmente, pode-se afirmar que a mulher arquiteta representa maior parcela no mercado de trabalho. Segundo o Conselho de Arquitetura e Urbanismo do Brasil (CAU, 2015), apenas dois estados brasileiros (Amapá e Acre) possuem a quantidade de arquitetos maior que a quantidade de arquitetas. Logo, no Brasil, mais da metade dos profissionais de arquitetura em atividade, mais precisamente $61 \%$, são mulheres e esse número só tende ao crescimento pois, jovens mulheres, de até 30 anos, representam a maior parcela de arquitetos e urbanistas da atualidade.

Circunstância essa previsível dentro das universidades, onde as mulheres já são a maioria. Tomo aqui como exemplo a Universidade Estadual Paulista "Júlio de Mesquita Filho" no campus de Bauru onde o curso de Arquitetura e Urbanismo é oferecido desde 1984. Dados dos Anuários Estatísticos (2018 e 2004) somados às informaçôes de documentos de Expedição de Registro de Diploma, informaçôes essas oferecidas pela Seção Técnica de Graduação da UNESP, elucidam o panorama geral sobre o gênero das pessoas já formadas: apenas as duas primeiras turmas da faculdade exibiu predominância quantitativa de homens, apresentando de 60\% a 70\% da turma. Da turma de 1986 até 2017, a quantidade de mulheres formadas ultrapassa de homens, representando sempre mais de $50 \%$ de cada turma.

Surge então uma problemática que se desdobra sobre o papel da prática projetual na construção do conhecimento acadêmico. Sendo o maior percentual de pessoas que cursam arquitetura pertencem ao grupo de mulheres e, tanto elas como seus colegas arquitetos, não possuem conhecimento da realidade da mulher arquiteta, a formação dos profissionais é incompleta. MUXÍ; MONTANER (2014) abordam o descompasso entre realidade e aprendizado da seguinte forma: "Crise da profissão é consequência do desajuste entre a cultura e a formação do arquiteto" (MUXÍ; MONTANER, 2014, p.38). A formaçáo do profissional é relacionada intimamente à cultura em que se encontra e consequentemente à ideologia a ela dependente.

O caminho percorrido pelo movimento feminista no Brasil é extenso e, ainda hoje, apesar de muitas conquistas, encontra dificuldades materializadas em atitudes como violência doméstica crescente, desigualdade salarial e baixa representatividade de mulheres em ambientes políticos, econômicos, em cargos de direção. Persiste, portanto, a internalização de uma ideologia de gênero construída pelo discurso do dominador para o dominado. O lugar de fala se faz necessário pois discussóes sobre diferentes tipos de opressão devem ser fomentadas com consciência que a pirâmide social tem em seu topo o homem branco heterossexual, colonizador que, por ter o poder de fala, tende a generalizá-lo. A representatividade, portanto, ostenta em si uma possibilidade inicial de mudança idearia, consequentemente cultural, sobre a situação de gênero na sociedade civil, trazendo para discussóes indivíduos que representam um grupo historicamente marginal: 
"Ao promover uma multiplicidade de vozes o que se quer, acima de tudo, é quebrar com o discurso autorizado e único, que se pretende universal. Buscase aqui, sobretudo, lutar para romper com o regime de autorização discursiva." (RIBEIRO, 2019, n.p.)

Uma vez que a "história comum" expõe a postura do dominante quanto aos fatos, a mulher como elemento dominado consequentemente é diminuída, suprimida ou excluída pela narrativa da realidade ideológica. Desta forma, é possível alimentar uma cultura de diminuição de mulheres não só no mundo real como também no mundo das ideias. E assim ocorre na historiografia de arquitetura:

a total, ou quase total ausência das mulheres como representantes dignas e legítimas do fazer arquitetônico ao longo da história leva a uma evidente deformação da ideia do campo profissional o que, em alguma medida, acaba por contribuir para a perpetuação da disparidade entre homens e mulheres no que diz respeito ao reconhecimento do direito de protagonizar legitimamente a produção profissional em seus diversos estágios. (LIMA, 2004, p. 112)

A partir do pressuposto que a base referencial das arquitetas e arquitetos é constituída na universidade através de inúmeras propostas de leitura, forma-se uma responsabilidade sobre a leitura indicada para o aluno e por qual contexto a história está sendo contada/escrita. A metodologia de LIMA (2004), em suma caracterizada pela presença de "modelos linguísticos masculinos" e "mecanismos de dominação simbólica" em textos acadêmicos, aplicada em clássicos da arquitetura como FRAMPTON (1997); ARGAN (1984); MONTANER (1993) e BENÉVOLO (2006), permite identificar que, aparentemente neutros, se mostram carregados de distinção de gênero, excluindo ou secundarizando a mulher. Em resumo, ARGAN (1984) e BENÉVOLO (2006) são muito parecidos no modo de repassar a história e reforçam "modelos linguísticos masculinos" através, principalmente, pela descrição do homem como "herói", "mestre" ou adjetivos que proponha grandeza, "cuja jornada de superação de obstáculos o leva à transcendência” (LIMA, 2004, p. 118). Assim, com ARGAN (1984) e BENÉVOLO (2006), FRAMPTON (1997) utilizou muito do "masculino genérico" onde a palavra "homem" que, na língua portuguesa, pode significar "espécie humana", interfere na identificação da mulher em alguma situação. Entretanto, tal problemática é ambígua pois pode também ser um problema de tradução do inglês para o português. Além disso,

No entanto, FRAMPTON (1997) e MONTANER (1993) se assemelharam pela abertura à pesquisa crítica advinda de figuras marginais da história, sendo esses os historiadores estudados mais abertos ao teor mutável da história arquitetônica. O propósito, portanto, não é contestar a originalidade ou maestria dos autores e sim identificar que o modo como a história é ensinada não considera a ideologia como fator de supressão de minorias. A leitura crítica-feminista da arquitetura anuncia uma metodologia fundamentada na leitura feita a partir do "lugar de fala" que, inevitavelmente, fortalece a manifestação de estudos de minorias.

A ascensão da mulher no campo projetual da arquitetura é praticamente simultânea ao surgimento da crítica propriamente latino-americana. Desde 1970, a arquitetura sofria grandes mudanças estruturais devido ao questionamento sobre o movimento moderno, indagando a desvalorização da história e a necessidade de criação de um novo "mundo". Na mesma década, o italiano Leonardo Benévolo, arquiteto e historiador de arquitetura, lança História da Arquitetura Moderna. O período foi marcado pelo medo político e militar em meio a guerras não armadas, assim como foi o período inicial para estabelecer diversos ideários que emergiram na década anterior. Segundo 
o autor, o movimento moderno, já muito decadente e temendo a perda de seguidores, incentiva o ressurgimento de concursos, exposiçôes e publicaçóes como métodos oficiais de comunicação com o público (BENÉVOLO, 2006).

Na década seguinte, absorvida essa ideia modernista sobre meios de comunicação, simultânea à maturidade da crítica global em "condição pós-moderna", a crítica tem maior relevância no cenário brasileiro e, é na revista especializada que encontra um espaço democrático de expressão. Segundo BASTOS e ZEIN (2010), a noção de "modernidade reflexiva", proporcionou "debates férteis que seguem alimentando as questóes arquitetônicas do começo do século XXI" (BASTOS; ZEIN, 2010, p.289). A partir dessa conceitualização é possível identificar o olhar marginal das autoras que afirmam a continuidade da história, considerando a uma construção lenta e ininterrupta, descartando o pensamento maniqueísta de "fim da modernidade" e "começo da pós-modernidade".

No Brasil, Anita Regina Di Marco, Ceça Guimaraes, Ruth Verde Zein e Cecília Rodrigues dos Santos exploram o campo midiático como forma de representação. Se destaca do grupo Ruth Verde Zein que, assim como Waisman na Argentina, fomenta, desde metade da década de 1970 até hoje, o debate crítico em periódicos, com a simples finalidade de "perceber tendências, levantar questôes, examinar certeza, fermentar dúvidas, agitar e impedir a autocomplacência e a acomodaçáo" (BASTOS; ZEIN, 2010, p. 292). Na revista, diferentemente do campo acadêmico que prioriza a neutralidade - mesmo que não há o que não seja político e, portanto, carregado de ideologias - a pesquisa carregada de ideários é aceita. E é, primeiramente na revista que, teoricamente, a relaçáo de feminismo e arquitetura podem ser amplamente refletidas e discutidas.

Assim, criada em 1972 como um boletim informativo do IAB-SP, com o nome de O Arquiteto, a revista Projeto tem sua história totalmente atrelada à construção da crítica arquitetônica no Brasil. As primeiras ediçóes, independentes, foram estruturadas pelo jornalista Vicente Wissenbach a partir de 1977, caracterizadas segundo CARMONA (2015) como:

"[...] muito enxutas, e em geral bimestrais, sem espaço ainda para a crítica de arquitetura, apenas apresentando projetos e pequenos textos de análise, além de propaganda e escritos técnicos." (CARMONA, 2015, p. 27)

A partir de 1979, pode-se dizer que a revista tem maior espaço para discussóes críticas sobre a arquitetura brasileira, principalmente depois do X Congresso de Arquitetura que ocorreu em Brasília com o tema A Arquitetura Brasileira após Brasília. Segundo MARQUES (1999), o título do congresso, pela primeira vez sugere discussão da arquitetura em si, ainda mais sobre Brasília, “inquestionada até entáo" (MARQUES, 1999, p.92).

Depois das revistas Habitat, Módulo (1950) e Acrópole (1960) seguirem para uma "linha editorial de tendência”, a revista Projeto juntamente à revista AU (desde 1985) marcaram o ressurgimento de publicaçóes regulares, agora em linha editorial crítica (SEGAWA; CREMA; GAVA, 2005). A proposta de abertura do meio arquitetônico para crítica foi proporcionada e intensificada pelo quadro mundial de restabelecimento de rupturas anteriores, crescimento populacional acelerado e início de resoluçóes da sociedade depois de momentos turbulentos de autoritarismo e guerras de ordem política, militar, tecnológica e principalmente ideológica. No Brasil, o processo de redemocratização foi determinante pois houve a abertura e estímulo à pesquisa através dos "primeiros cursos de pós-graduação no país [...]" e "o crescimento das editoras com espaços para publicaçóes específicas na área de arquitetura” (CARMONA, 2005, p.12).

[...] nos anos 80 começou a surgir pelo menos o embriáo de uma atitude geral e de uma imprensa mais críticas. Eu citaria a revista Projeto, por um lado não 
muito crítica na apresentação dos projetos, mas por outro bastante aberta a diferentes correntes, apresentando também textos teóricos, na seção Ensaio \& Pesquisa. Ensaios, aliás, que começaram tímidos, citando principalmente autores estrangeiros, para depois evoluir e se aprofundar criticamente. (VÁRIOS AUTORES. Debate crise anos 80. PROJETO, ed. 129, 1990, p. 155., apud. CARMONA, 2015, p. 24)

Portanto, durante a década de 1980, a Revista Projeto consolida no Brasil uma forma de conhecimento crítico responsável pela veiculação periódica de ideias que influenciaram a prática profissional do período. A aproximação à revista argentina Summa, concomitantemente ao trabalho de Ruth Verde Zein e Hugo Segawa - primeiros arquitetos jornalistas colaboradores da revista - foram de notável importância para "uma nova crítica brasileira", baseada na premissa inicial de Wissenbach sobre ser "porta-voz de todos os arquitetos" (PROJETO, ed. 42, 1982, p. 41).

\section{METODOLOGIA}

Dado panorama crítico do Brasil na década supracitada, entende-se a importância da revista Projeto como referencial crítico da arquitetura. Assim, se mostra como grande fonte para uma pesquisa crítica sobre a representatividade de mulheres arquitetas, dada sua abordagem e objetivo como periódico na década de 1980. Relacionado à esse panorama, a matéria História da Arquitetura IV, ministrada pela Professora Kelly Cristina Magalhães, aplicada em 2018 na Universidade Estadual Paulista (UNESP), teve como mote principal a experimentação de ensino de história da arquitetura que, através da perspectiva de gênero atrelada à pesquisa em revista, propôs a pesquisa crítica da arquitetura em desenvolvimento nos períodos de 1980 e 1990. Em suma, a matéria produziu 16 levantamentos contendo, cada um, uma ficha catalográfica (Figura 1), cópia do trecho da revista que se refere à mulher e um texto/prancha analítica sobre projetos de mulheres publicados na revista Projeto.

Figura 1 - Ficha Catalográfica História da Arquitetura IV, frente e verso.

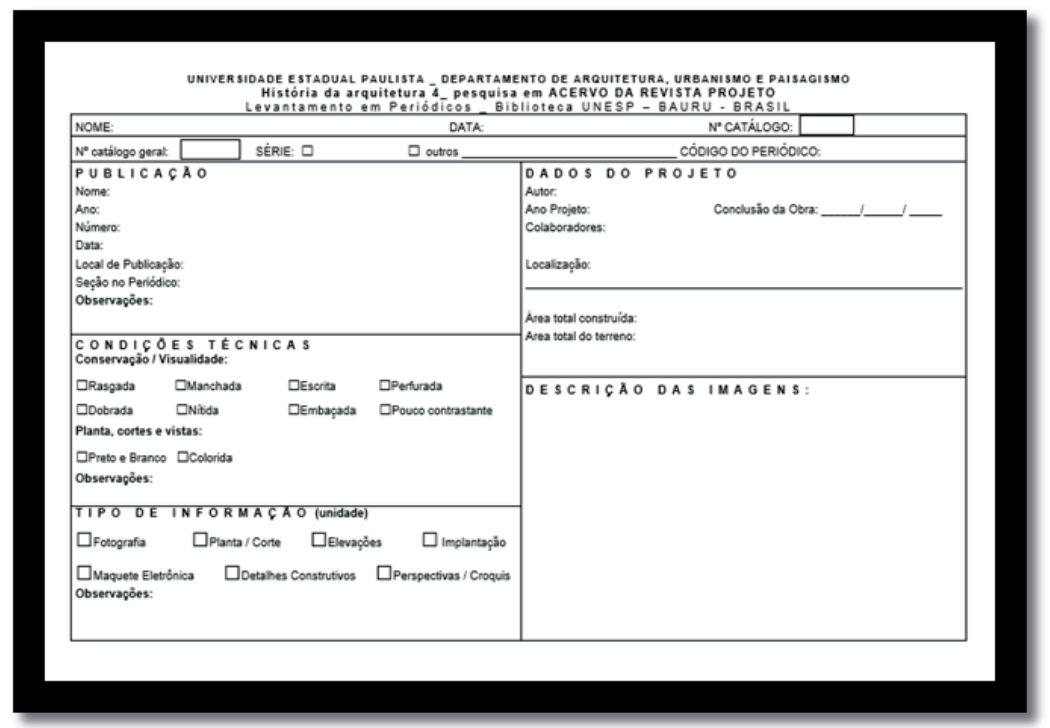




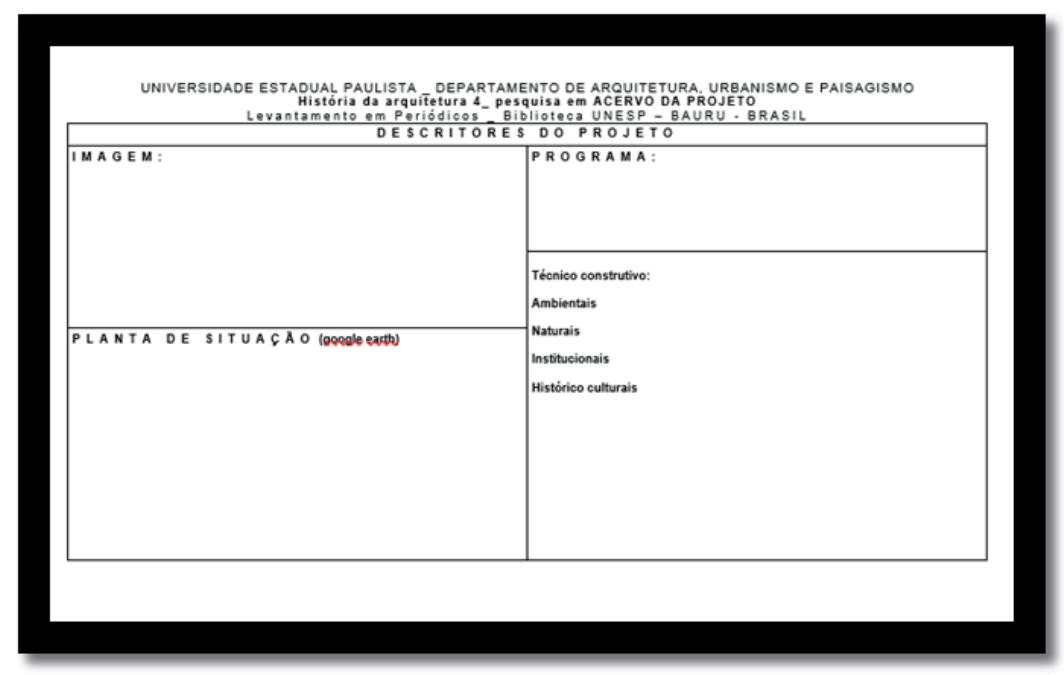

Fonte: Professora Doutora Kelly C. Magalhães.

A partir do acervo da revista Projeto, disponível em exemplares físicos na Biblioteca UNESP, Campus Bauru, referente ao período tratado, as fichas produzidas pela matéria de História da Arquitetura VI foram alteradas para que alcançassem dois objetivos principais: quantificar as mulheres que eram apresentadas na revista, tanto na comissão e conselho editorial como aquelas autoras de projetos, além de qualificar o modo de abordagem do periódico, do mesmo modo que foram analisados livros/manuais de arquitetura. A ficha foi elaborada para dar suporte à pesquisa, concentrando as informaçóes em apenas uma fonte.

Dessa maneira, os dados foram fragmentados em duas partes. Compondo a primeira etapa estáo as duas primeiras páginas (Figura 2), com objetivo principal de, primeiramente, nomear o periódico através do seu número de publicação, data de publicação, seção do periódico que vai se tratar, condiçôes físicas gerais, quais os tipos de informaçôes gráficas que contém, qual a composição feminina da administração e pesquisadoras da revista, com nomes e funçôes. Logo após reconhecimento da comissão e conselho editorial, o objetivo é identificar quais e quantas mulheres tiveram papel de protagonismo na revista, ou seja, apontar qual o produto daquela mulher para esse meio midiático e quantas páginas da revista foi ocupada por ela. Ao final desse primeiro fragmento, encontrou-se uma necessidade de fazer observações, que seriam peculiaridades até então encontradas da unidade da revista, além de análises prévias já constatadas. 
Figura 2 - Primeira parte da Ficha Catalográfica. Projeto n¹7.

UNIVERSIDADE ESTADUAL PAULISTA _ FAAC - FACULDADE DE ARQUITETURA, ARTES E COMUNICAÇÃO Trabalho Final de Graduaçäo "Mulheres Arquitetas: análise da trajetória profissional na Revista Projeto na década de 1980"
Levantamento nos Periódicos "Projeto" (1980-1990) - Biblioteca UNESP - BAURU - BRASIL

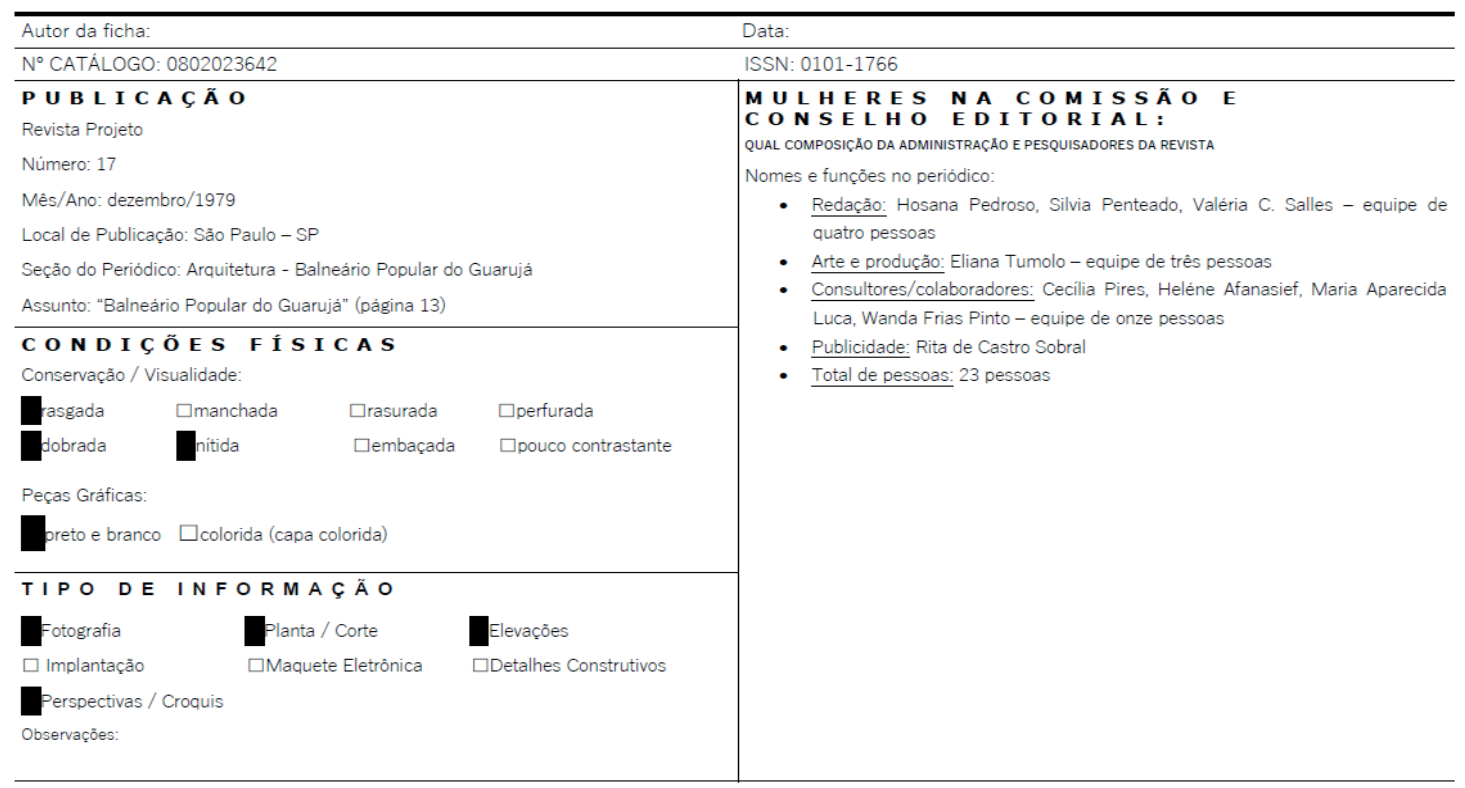

\begin{tabular}{|c|c|}
\hline $\begin{array}{l}\text { M U L H E R E S E M P R O J E T O S : } \\
\text { QUAIS E QUANTAS MULHERES TIVERAM PAPEL PRINCIPAL No PERIóoico } \\
\text { 1. Artigo: Balneário Popular do Guarujá } \\
\text { Quem escreveu: } \\
\text { Seção do Periódico: Projeto/Lazer } \\
\text { Arquiteta: Odiléia Toscano } \\
\text { Páginas: } 5 \\
\text { 2. Artigo: O intenso debate sobre as condições de produção da arquitetura } \\
\text { brasileira } \\
\text { Quem escreveu: Hosana Pedroso } \\
\text { Seção do Periódico: Congresso/Panorama } \\
\text { 3. Artigo: Conforto acústico, desempenho, adequação ao projeto: fatores } \\
\text { determinantes na escolha } \\
\text { Quem escreveu: Maria Aparecida Camargo de Luca } \\
\text { Seção do Periódico: Revestimentos }\end{array}$ & $\begin{array}{l}\text { Observaçães: } \\
\text { - Das quatro obras selecionadas pela revista, apenas uma tinha como responsável } \\
\text { uma mulher; } \\
\text { - No sumário da revista, ao apresentar as obras que vinham adiante, a de Odiléia foi } \\
\text { a única apresentada pelo último nome da arquiteta, o restante foi apresentado } \\
\text { nome e sobrenome dos arquitetos: } \\
\text { Artigo " Balneário Popular do Guarujá - Fala-se muito dos problemas criados } \\
\text { pelos "farofeiros", mas pouco se faz para dar mais de conforto ao povão no seu } \\
\text { merecido e dificil descanso. Por isso é sempre gratificante poder publicar um } \\
\text { projeto como o de Toscano. Página } 13 \text { e seguintes. } \\
\text { "Edificio sede da Terrafoto - Nesse número, publicamos o projeto vencedor do } \\
\text { concurso nacional para a sede da empresa. Seus autores, os paranaenses } \\
\text { Leonardo Oba, Guilhereme Zamoner Neto e Joel Ramalho Jr. Mostram o projeto } \\
\text { na página } 19 \text { e seguintes." } \\
\text { "Habitação coletiva em Minas - Aras. Éolo Maia e Márcio Lima. Págs. } 25 \text { e 26." } \\
\text { "Mercado Municipal de Bebedouro - Aras. Sidney Rodrigues e João Valente Filho } \\
\text { Págs. } 31 \text { e } 32 \text { " } \\
\text { - Na capa, o projeto do "Balneário Popular do Guarujà" é atribuido à João Walter } \\
\text { Toscano enquanto no artigo, é atribuido à Odiléia Toscano: "Balneário Popular. } \\
\text { chegou a vez do povão no Guarujả. Projeto de João Walter Toscano." } \\
\text { - De } 23 \text { pessoas que trabalham na revista, } 9 \text { são mulheres; ou seja, 39.1\% da } \\
\text { revista são mulheres; } \\
\text { - Os cargos mais altos (Presidentes honorários, Editor, Diretor Comercial, Revisor, } \\
\text { Supervisor gráfico) não são ocupados por mulheres nessa edição }\end{array}$ \\
\hline
\end{tabular}

Fonte: Autora.

O segundo fragmento (Figura 3), composto pelas duas últimas páginas, tem o intuito de evidenciar uma das contribuiçóes projetuais selecionadas pela revista e protagonizadas por mulheres, valorizando seu trabalho. Esta etapa demonstra a prática projetual de arquitetas, conhecendo a formação acadêmica, sua área de atuação e o contexto em que se encontra, além dos dados técnicos de projeto como programa, colaboradores, localização, se espaços públicos ou privados e qual tipo 
de espaço, quais peças gráficas encontradas no periódico e as melhores imagens que representam o projeto. Esse ensaio permite ampliar as referências dentro do meio acadêmico, possibilitando a reflexão sobre projetos de arquitetura até então pouco aprofundados e cria um acervo com informaçóes ainda pouco coletadas.

Figura 3 - Segunda parte da Ficha Catalográfica. Projeto nº17. UNIVERSIDADE ESTADUAL PAULISTA - FAAC - FACULDADE DE ARQUITETURA, ARTES E COMUNICAÇÃO
Tra Levantamento nos Periódicos "Projeto" (1980-1990) B Biblioteca UNESP - BAURU - BRASIL

\begin{tabular}{|c|c|}
\hline \multicolumn{2}{|c|}{ PRO J E T O } \\
\hline $\begin{array}{l}\text { A A R Q U I T E T A } \\
\text { IDENTIFICAR A ATUAÇÃO DA ARQUITETA NA ÁREA ACADÉMICA E MERCADO DE TRABALHO }\end{array}$ & $\begin{array}{l}\text { C O N T E X T O : } \\
\text { BREVE CONTEXTUALIZACAO DO PERIODO DE CONCEPCAO DA OBRA }\end{array}$ \\
\hline Nome: Odiléa Helena Setti Toscano & O final da década de 70 , década de 80 e começo de 90 representaram para a história, em geral, \\
\hline Periodo de Formação Acadêmica: 1953 - 1958 (USP) & momento de restabelecimento de rupturas anteriores, crescimento populacional acelerado e \\
\hline Local: São Paulo & $\begin{array}{l}\text { Inicio de resoluçoes da sociedade depols de momentos turbulentos de autoritarismo e guerras } \\
\text { de ordem politica, militar, tecnológica e principalmente ideolósica. O Brasil encontrava-se em um }\end{array}$ \\
\hline Escritório: - & processo de redemocratização depois de um longo periodo em uma ditadura, democracia essa \\
\hline Especialização/ärea: arquiteta, professora e artista plástica & consolidada através da constituiçẫo em 1988. Na arquitetura, o começo do século representou a \\
\hline $\begin{array}{l}\text { observaçōes: graduação atrelada às discussōes sobre a arquitetura moderna; mulher de João } \\
\text { Walter Toscano, também arquiteto, com quem passa a desenvolver projetos conjuntos. }\end{array}$ & $\begin{array}{l}\text { separação oficial entre as práticas de arquitetos e engenheiros, além da intensa divulgação e } \\
\text { consolidação da arquitetura moderna como um discurso social e estético. }\end{array}$ \\
\hline $\begin{array}{l}\text { D A D O S D o P R O J E T O } \\
\text { Projeto: Balneário Popular do Guarujá }\end{array}$ & $\begin{array}{l}\text { P R O G R A M A : } \\
\text { DESCRICAO DO PROGRAMA DA CONSTRUCAO: DESCRICAO DA TĖCNICA CONSTRUTIVA, FATORES } \\
\text { AMBIENTAIS DO LOCAL, RELAÇAO COM O EXTERIOR. FATORES HISTORICO - CULTURAIS OBSERVADOS. }\end{array}$ \\
\hline Autor: Odiléa Toscano & Programa: vestiários e sanitários, administração e serviços, parque infantil com berçário, salão \\
\hline Colaboradores: João Walter Toscano, Massayoshi Kamimura & de uso múltiplo, estacionamento, atividades de lazer e recreativas; Técnico construtivo: "Evitar \\
\hline Ano execução: (não construida) & seccionamentos visuais e de funcionamento de área. Considerar os problemas de trănnsito como \\
\hline Localização: Guarujá - SP (entorno da praia do Perequê) & $\begin{array}{l}\text { jardins para descanso, passeio, dispersos entre árvores, arbustos, água etc." (p. 14); Naturais: } \\
\text { "(-) situada junto à praia do Perequê, se refere ao limite definido pelo contorno da curva de }\end{array}$ \\
\hline CONSTRUÇ & $\begin{array}{l}\text { ivel (cota } 5 \text { ) e abrange o setor da planicie costeira disponivel para a urbanizaçâo, fazendo parte } \\
\text { de um grande anfiteatro onde o Rio Perequê, juntamente com os maciços mais elevados dos }\end{array}$ \\
\hline Área total construida: $200.000,00 \mathrm{~m}^{2}$ & morros, tem grande importância na organização da paisagem." (p. 13); Institucionais: "Os \\
\hline & equipamentos de recreação e instalaçôes serăo considerados como parte fundamental para a \\
\hline nal $\square$ Interiores $\square$ Reforma $\square$ Paisagismo & $\begin{array}{l}\text { Wuatis } \\
\text { turismo na Estância do Guarujá revela desde logo o surgimento de um novo tipo de turismo, }\end{array}$ \\
\hline Privado $\quad \square$ Público $\quad \square$ Semiprivado & estruturalmente diverso do turismo de veraneio: o turismo de massas" (p. 13) \\
\hline
\end{tabular}




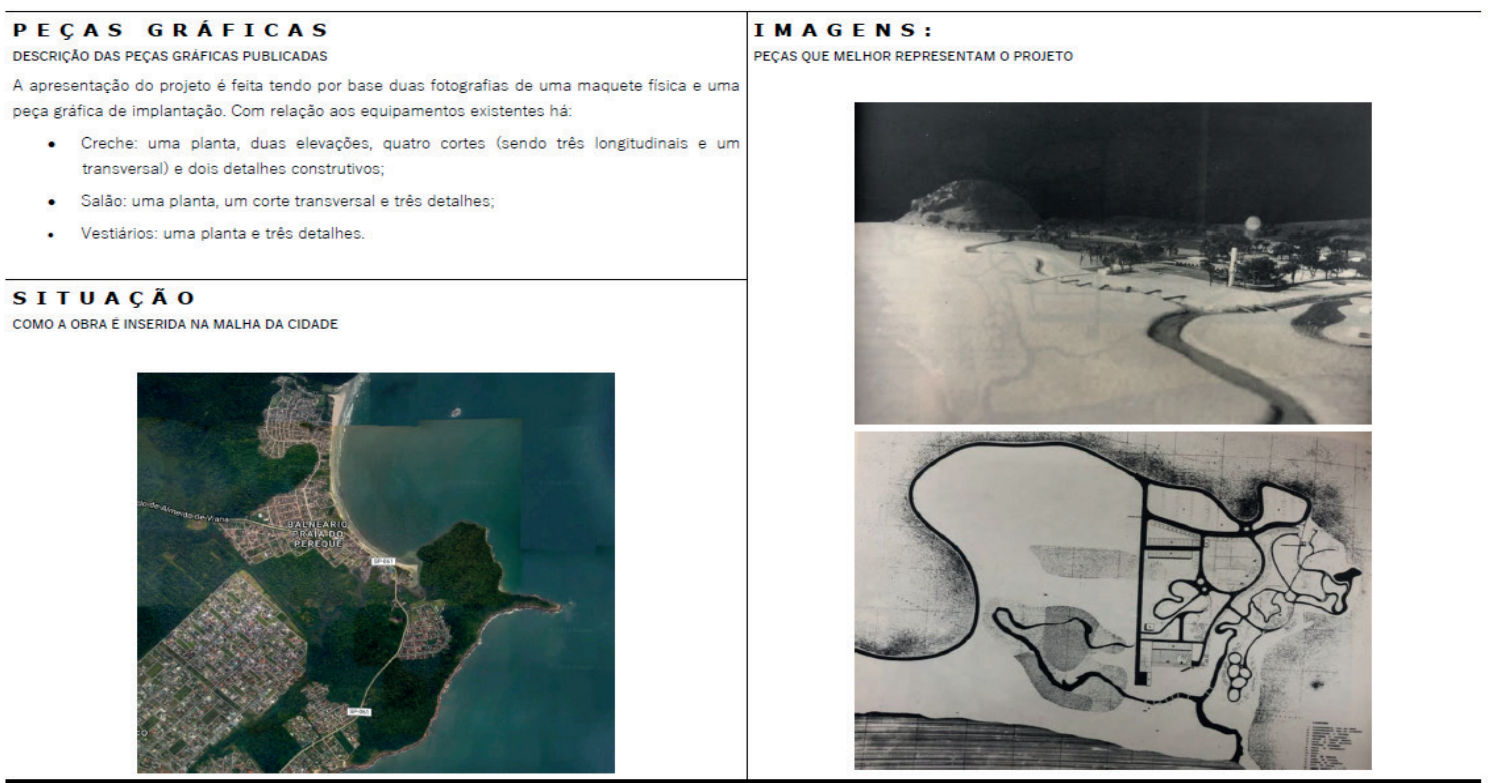

Fonte: Autora.

Portanto, com base na análise de referenciais bibliográficos e a partir do levantamento de dados projetuais e de discurso, procura-se visibilizar o modo como a produção de mulheres é apresentada em documentos históricos periódicos. Consequentemente, os resultados permitem a construção de argumentos que ajudam a ampliar o reconhecimento do estudo de gênero associado à prática projetual, embasando assim diretrizes para viabilizar o estudo de gênero como categoria essencial de análise acadêmica do projeto de arquitetura. $\mathrm{O}$ trabalho identifica, analisa e evidencia a produção de mulheres, no período pós Segunda Guerra Mundial, questionando a falta de representatividade dessas no ensino de arquitetura até hoje, mesmo que essas sejam em maior quantidade em salas de aula e mercado de trabalho. Logo, comprova-se a importância de um pensamento crítico sobre o estudo de gênero dentro da universidade.

A pesquisa evidencia, como base metodológica, a abordagem dialética, já que os fatos não podem ser revelados por completo fora de seu contexto e realidade histórico-social, abrangendo política e economia. Simultaneamente, enquadra-se como pesquisa exploratória de natureza aplicada pois, ao mesmo tempo que enfatiza novo enfoque ao assunto de gênero em sala de aula universitária tendo o periódico informativo como objeto de estudo, busca gerar conhecimentos necessários para a aplicação prática da resolução do problema específico de escassez de representatividade no ensino da disciplina de arquitetura.

\section{RESULTADOS}

No artigo Diversidade não é igual à pluralidade, de Kischinhevsky e Chagas (2017), a premissa defendida é que os conceitos do título - diversidade e pluralidade - são basilares para um jornalismo 
democrático. Quantificar a presença de mulheres em determinado espaço de produção textual periódica significa saber, portanto, se a base de produção desse meio de comunicação possui pessoas de diferentes sexos que, consequentemente, possuem diferentes experiências individuais:

É necessário, em suma, garantir tanto a pluralidade de fontes, com uma representatividade dos atores sociais, quanto a diversidade, com a incorporação de outras vozes além daquelas identificadas com o poder público e os grupos políticos e econômicos mais organizados para assegurar acesso contínuo aos meios de comunicação. (KISCHINHEVSKY; CHAGAS, 2017)

Para tanto, primeiramente foram analisadas a comissão e conselho editorial, setores que operam a revista. De acordo com os 16 casos analisados, a quantidade de mulheres que trabalhavam para fazer a revista náo passou de $41 \%$ do total de pessoas que faziam parte da produção. A maior distribuição de mulheres na revista pode ser encontrada no ano de 1990 (PROJETO, v. 133 e PROJETO, v. 134), quando $40,3 \%$ dessa área era composta pelo sexo feminino. Ou seja, a representatividade na produção da revista Projeto, não chegava a ser ao menos igualitária na década de 1980, sendo a predominância masculina uma constante. No começo na década, ad disparidade ainda era maior - a quantidade de homens que compunham a produção da revista chegou a $75 \%$ do total.

Reveladas comissão e conselho editorial, a análise é feita quando a referência projetual que o periódico escolhe exibir. A partir da quantidade total de projetos expostos pela revista, foram quantificados e classificados os projetos pela maneira de participação das mulheres em cada um: se exclusivamente feitos por uma mulher ou homem, se em equipes lideradas por uma mulher, se em equipe com a mulher em papel secundário ou se não identificado, quando não há atribuição do projeto à pessoas mas sim à um escritório com nome que, não necessariamente é atribuído a um homem. Apenas as classificaçôes "exclusivamente mulheres" e "equipe lideradas por mulheres" foram contabilizadas como autoria feminina, visto o protagonismo dessas no projeto.

Assim, das revistas analisadas, apenas uma (PROJETO, v. 118, 1989) tem mais da metade das autorias dos projetos atribuídos às mulheres, chegando à $62,5 \%$, o máximo alcançado pela revista no período. Essa edição, de janeiro de 1989, considerada como exceção à regra da visibilidade feminina na revista em geral, tem como mote principal o desconstrutivismo e, de oito projetos, cinco tinham protagonismo feminino, destacando-se a obra de Lina Bo Bardi, arquiteta já consagrada e que faz parte do star system brasileiro. Das revistas analisadas, essa é a primeira em que uma mulher foi responsável por um cargo gerencial de revisora, Maria Luiza Simões.

Em contrapartida, as outras quinze revistas analisadas indicam o oposto, já que a média de projetos de autorias de mulheres ficou em $24,3 \%$ do total. Os melhores indicativos acontecem no ano de 1988 e 1989, com 62,5\% (PROJETO, v. 118, 1989), 42,9\% (PROJETO, v. 112, 1988) e 35,3\% (PROJETO, v. 110, 1988). Os piores se encontram nos anos de 1987, com 9,1\% (PROJETO, v. 100, 1987) da comissão e conselho composto por mulheres, seguido dos anos de 89 e 90, com 10\% (PROJETO, v. 128, 1989 e PROJETO, v. 134, 1990) e 11,1\% (PROJETO, v. 133, 1990) do todo.

Diante da análise quantitativa, é possível também aplicar uma análise de abordagem da revista para com as arquitetas selecionadas e apresentadas. Apesar dos discursos sobre projetos serem, em sua maioria, muito descritivos e pouco críticos, podemos fazer algumas observaçóes e apontamentos. As capas das revistas, por exemplo, além de ter a função de apresentar o conteúdo que vai seguir, empenham papel de atrair o leitor do periódico. 
A capa da Revista Projeto no 17 representa uma constante de obscurecimento das atividades de arquitetas. Primeiramente, o projeto do "Balneário Popular do Guarujá" é atribuído, na capa, à João Walter Toscano ("Balneário Popular: chegou a vez do povão no Guarujá. Projeto de João Walter Toscano." (PROJETO, v. 17, 1979), divergindo assim como o projeto é apresentado no artigo, atribuído à arquiteta Odiléia Toscano, mulher do arquiteto João Toscano. Ainda, no sumário, ao apresentar as obras que vinham adiante, a da arquiteta foi a única apresentada pelo último nome, os demais arquitetos foram apresentados pelo nome e sobrenome, da seguinte maneira:

"Artigo "Balneário Popular do Guarujá - Fala-se muito dos problemas criados pelos "farofeiros", mas pouco se faz para dar mais de conforto ao povão no seu merecido e difícil descanso. Por isso é sempre gratificante poder publicar um projeto como o de Toscano. Página 13 e seguintes.

"Edifício sede da Terrafoto - Nesse número, publicamos o projeto vencedor do concurso nacional para a sede da empresa. Seus autores, os paranaenses Leonardo Oba, Guilhereme Zamoner Neto e Joel Ramalho Jr. Mostram o projeto na página 19 e seguintes."

"Habitação coletiva em Minas - Arqs. Éolo Maia e Márcio Lima. Págs. 25 e 26."

"Mercado Municipal de Bebedouro - Arqs. Sidney Rodrigues e João Valente Filho Págs. 31 e 32" (PROJETO, v. 17, 1979)

É possível constatar que, Odiléia Helena Setti Toscano, arquiteta, professora e artista plástica paulista, graduada em 1958 pela Universidade de São Paulo (GOLDCHMIT, 2008), assim como a brasileira Carmen Portinho e a africana Denise Scott Brown, foi "eclipsada" por seu cônjuge. Devido à essa maneira de construção histórica, a participação efetiva de mulheres em projetos arquitetônicos é "submetida à uma operação de "eclipse"” (LIMA, 2004, p. 135).

Nas ediçốes subsequentes, a "operação de "eclipse"” da mulher pelo homem também pode ser identificada, porém de outra maneira. As arquitetas Marília Sant'anna de Almeida (PROJETO, v. 24, 1980), Thêmis da Cruz Fagundes e Maria Alice Silva Torres (PROJETO, v. 39, 1982) foram referenciadas pelo substantivo masculino "arquiteto" e, utilizar o masculino indistintamente, dá margem a esse fenômeno de marginalização da figura feminina. No entanto, empregar o masculino genérico dessa maneira se mostra como um problema etimológico que não atinge exclusivamente o discurso de homens, sendo algo presente também na fala de mulheres:

"Ao arquiteto cabe a responsabilidade da natureza essencial do projeto, o desenho arquitetônico e urbanos e seus caráter determinante na composição de um habitat humano." (PROJETO, v. 39, 1982, grifo da autora)

"O lugar do homem numa paisagem idílica na praia." (PROJETO, v. 114, 1988, grifo da autora)

Apenas uma das ediçóes estudadas possui o nome de uma mulher na capa (PROJETO, v. 133, 1990), Lina Bo Bardi, arquiteta do star system brasileiro que, ainda assim, divide a página inicial com Rem Koolhas. Nessa edição, percebe-se que a seção Carta do Editor que, por via de regra tem característica de manifesto do editor/editores sobre um assunto específico a ser abordado no periódico, tem sua premissa alterada. Com o título "A poética de uma arquiteta maior", faz-se entender que o responsável iria escrever sobre a arquiteta Lina Bo Bardi, chamada principal da capa 
da revista. E assim se faz, iniciando-se o texto com "Esta edição é uma homenagem a um dos mais importantes arquitetos brasileiros: Lina Bo Bardi.". No entanto, depois de um parágrafo falando sobre a arquiteta, como se não tivesse mais a falar, alterou a configuração da carta para um resumo sobre os assuntos que a revista trataria, se alongando mais sobre o tema de concursos de arquitetura.

O objetivo inicial de Wissenbach sobre a revista Projeto ser "porta-voz de todos os arquitetos" (PROJETO, ed. 42, 1982, p. 41, grifo da autora) é alcançado, porém como substantivo masculino. De fato, abranger a diversidade e pluralidade dos produtos culturais - no caso, arquitetônicos - de uma sociedade é uma tarefa difícil. Em um período de ascensão da crítica arquitetônica brasileira, a representatividade feminina em um veículo de informaçóes críticas, é baixíssima. Contudo, a presença de mulheres arquitetas no periódico, comprova a atuação desse grupo marginal. Identificar tais indivíduos representa a fase inicial para atribuir importância à sua produção arquitetônica e, além disso, refletir sobre a realização desse grupo.

Desse modo, a pesquisa em revista abordando perspectiva feminista através da análise contextual e de discurso, representa uma possibilidade de reconstrução da história a partir de uma visão contemporânea. Esse tipo de diretriz viabiliza o estudo de gênero como categoria de análise acadêmica arquitetônica e propicia meio adequado para que a história seja passada através de um olhar marginal e crítico sobre a realidade de figuras que constroem massivamente a profissão. Através do estudo de dezesseis revistas, e fichamento de informaçóes, as arquitetas Odiléia Toscano, Marília Sant'anna de Almeida, Thêmis da Cruz Fagundes, Maria Alice Silva Torres, Deisi Lopes de Oliveira, Kátia Araújo, Miriam Escobar, Cátia Avellar, Maria Cristina Bittar B. da Costa, Lina Bo Bardi, Beatriz Dorfmann Levy, Marisa Soibelman, Anne Marie Sumner e Ione Mota Marroquim foram colocadas protagonistas da própria produção.

\section{CONSIDERAÇÕES FINAIS}

A questão de gênero no ensino de arquitetura deve ser abordada nos cursos com o objetivo de discutir, com alunas e alunos, a realidade de falta de representatividade, admitindo o conhecimento sobre a história de marginalizados como modo de solucionar esse grande descompasso entre a base de estudos e o campo profissional. A partir do estudo de gênero, é possível constatar que o crescimento gradual da visibilidade de arquitetas náo se configura como um fato isolado de sorte ou evolução espontânea, e sim como consequência da luta feminista, não só do campo arquitetônico.

Desse modo, defendo a gradual mudança epistemológica através de desconstruçôes linguísticas advindas principalmente de professoras e professores e, consequentemente, integradas por alunas e alunos. Rever a aplicação do masculino indistinto, assim como referenciar mulheres antes de homens, são formas fundamentais e primárias, no meio acadêmico, de compreender gênero como uma construção social que demanda mudança. Destacar diferentes abordagens sobre fatos históricos podem também estimular a crítica ao assunto, resultando na reeducação sobre o significado de ideologia para grupos sociais antes ignorados.

No campo arquitetônico, a revista especializada é um importante instrumento de conhecimento sobre a profissão, visto sua periodicidade de conteúdo específico e grande liberdade crítica. $\mathrm{O}$ material resultado da pesquisa em periódicos possibilita identificaçáo e valorizaçáo do projeto arquitetônico de diferentes arquitetas. Essa compilação de nomes de mulheres arquitetas latino-americanas revela a inevitável influência dessas na profissão, academicamente ou em capo prático, como contemporâneas a momentos importantes da arquitetura de ponderação sobre o movimento 
moderno, redemocratização no Brasil e estabelecimento de uma cultura de crítica em diversos campos teóricos.

Abordar a perspectiva de gênero na revista representa uma possibilidade de diretriz que viabiliza o estudo de gênero como categoria de análise acadêmica, propiciando meio adequado para que a história seja passada através de um olhar marginal sobre essas figuras em relação à profissão. Devido ao fato de a mulher ser marginalizada pela sociedade e se diferenciar historicamente e culturalmente do homem, é viável caracterizar sua produção arquitetônica diferente daquela produzida pelo grupo protegido pela ideologia vigente. Tal fator desdobra na possibilidade de estudos de outros grupos marginalizados, assim como desvela a urgência de identificar as mulheres negras na arquitetura e como essas vem conciliando seus conhecimentos técnicos a partir de seu "lugar de fala".

A contextualização como uma forma de conhecer as experiências individuais do outro e, portanto, se adentrar no seu ponto de vista, se faz essencial para o conhecimento do movimento feminista. Politizar-se e informar-se é fundamental e o primeiro passo para que a ideologia não se sobreponha a diferentes pensamentos e culturas que uma sociedade pode expressar. A arquitetura, como produto cultural intrínseco aos seres sociais, deve ser estudada de acordo com seu contexto histórico e, vincular às circunstâncias de grupos marginalizados preenche lacunas até então pouco exploradas.

\section{REFERÊNCIAS}

AAA. Alternativas. In: MONTANER, Josep Maria; MUXI, Zaida. Arquitetura e Política: ensaios para mundos alternativos. São Paulo: Gustavo Gili, 2014. p. 13-78. Traduçáo de Frederico Bonaldo.

ARGAN, Giulio Carlos. Walter Gropius e a Bauhaus. Lisboa: Editorial Presença, 1984. 143 p. Tradução de: Emilio Campos Lima.

BASTOS, Maria Alice Junqueira; ZEIN, Ruth Verde. Brasil: Arquiteturas após 1950. São Paulo: Perspectiva, 2010.

BOURDIEU, Pierre. A dominaçáo masculina. 3. ed. Rio de Janeiro: Bertrand Brasil, 2003. 160 p. Tradução de Maria Helena Kühner.

CARMONA, Jaime Soares. Crítica de arquitetura no Brasil: 1985-2010. 2015. 168 f. TCC (Graduação)

- Curso de Arquitetura e Urbanismo, Universidade de São Paulo, São Paulo, 2015.

CHAUÍ, Marilena. O que é ideologia? Disponível em: < https://edisciplinas.usp.br/pluginfile.php/388158/ mod_resource/content/1/Texto\%2014\%20-\%20O\%20que\%20\%C3\%A9\%20ideologia\%20-\%20M.\%20 Chau\%C3\%AD.pdf>. Acesso em: 21 mai. 2019.

CONSELHO DE ARQUITETURA E URBANISMO DO BRASIL (Brasil). Censo dos Arquitetos e Urbanistas do Brasil. 2017. Disponível em: < https://www.caubr.gov.br/wp-content/uploads/2018/03/ Censo_CAUBR_06_2015_WEB.pdf>. Acesso em: 24 maio 2019.

CONSELHO DE ARQUITETURA E URBANISMO DO BRASIL (Brasil). Sistema de Inteligência Geográfica. 2017. Disponível em: < https://igeo.caubr.gov.br/publico/>. Acesso em: 25 maio 2019. 
CREMA, Adriana; SEGAWA, Hugo; GAVA, Maristela. Revistas de arquitetura, urbanismo, paisagismo e design: a divergência de perspectivas. Arquitextos, São Paulo, ano 05, n. 057.10, Vitruvius, fev. 2005 http://www.vitruvius.com.br/revistas/read/arquitextos/05.057/506

FRAMPTON, Kenneth. Introdução. In: FRAMPTON, Kenneth. História crítica da arquitetura moderna. 3. ed. São Paulo: Martins Fontes, 1997. p. IX-XII.

FRAMPTON, Kenneth. Parte 3 - Avaliação Crítica e extensão até o presente: 1925-91. In: FRAMPTON, Kenneth. História crítica da arquitetura moderna. 3. ed. São Paulo: Martins Fontes, 1997. Parte 3. p. 301-417.

FRAMPTON, Kenneth. Prefácio à terceira edição. In: FRAMPTON, Kenneth. História crítica da arquitetura moderna. 3. ed. São Paulo: Martins Fontes, 1997. p. VII-VIII.

GOLDCHMIT, Sara Miriram. Odiléia Setti Toscano: do desenho ao design. 2008. 156 f. Dissertação (Mestrado) - Curso de Design e Arquitetura, Prof. Dr. Silvio Dworecki, São Paulo, 2008.

IBGE - INSTITUTO BRASILEIRO DE GEOGRAFIA E ESTATÍSTICA. Estatísticas de Gênero: Indicadores sociais das mulheres no Brasil. 2018.

JAPIASSÚ, Hilton; MARCONDES, Danilo. Dicionário Básico de Filosofia. 3. ed. Rio de Janeiro: Jorge Zahar Editor, 2011.

KISCHINHEVSKY, Marcelo; CHAGAS, Luãn. Diversidade não é igual à pluralidade: Proposta de categorização das fontes no radiojornalismo. Galáxia (São Paulo), [s.1.], n. 36, p.111-124, dez. 2017. FapUNIFESP (SciELO). http://dx.doi.org/10.1590/1982-2554233396.

LEONARDO BENÉVOLO. História da arquitetura moderna. São Paulo: Perspectiva, 1976.

LIMA, Ana Gabriela Godinho et al. Arquitetas e arquitetura a América Latina no século XX. São Paulo: Altamira Ediçâo, 2014. Disponível em: <\&lt;https://femininoeplural.files.wordpress.com/2014/03/arquitetasalxx_final.pdf\&gt;>. Acesso em: 13 mar. 2019.

LIMA, Ana Gabriela Godinho. Revendo a história da arquitetura: uma perspectiva feminista. 2004. 179 f. Tese (Doutorado) - Curso de Arquitetura e Urbanismo, Faculdade de Educação, Universidade de São Paulo, São Paulo, 2004.

MONTANER, Josep Maria. A modernidade superada: Ensaios sobre arquitetura contemporânea. Trad. Alicia Penna. 2 ed. rev. e ampl. São Paulo: Gustavo Gili, 2012.

PROJETO: Arquitetura, planejamento, desenho industrial, construçáo. São Paulo: Projeto Editores Associados Ltda., v. 17, dez. 1979. Mensal. ISSN 0101-1766

PROJETO: Arquitetura, planejamento, desenho industrial, construção. São Paulo: Projeto Editores Associados Ltda., v. 24, out./nov. 1980. Mensal. ISSN 0101-1766

PROJETO: Arquitetura, planejamento, desenho industrial, construçáo. São Paulo: Projeto Editores Associados Ltda., v. 39, abr. 1982. Mensal. ISSN 0101-1766 
PROJETO: Arquitetura, planejamento, desenho industrial, construçáo. São Paulo: Projeto Editores Associados Ltda., v. 95, jan. 1987. Mensal. ISSN 0101-1766

PROJETO: Arquitetura, planejamento, desenho industrial, construçáo. São Paulo: Projeto Editores Associados Ltda., v. 98, abr. 1987. Mensal. ISSN 0101-1766

PROJETO: Arquitetura, planejamento, desenho industrial, construçáo. São Paulo: Projeto Editores Associados Ltda., v. 100, jun. 1987. Mensal. ISSN 0101-1766

PROJETO: Arquitetura, planejamento, desenho industrial, construçáo. São Paulo: Projeto Editores Associados Ltda., v. 110, mai. 1988. Mensal. ISSN 0101-1766

PROJETO: Arquitetura, planejamento, desenho industrial, construçáo. São Paulo: Projeto Editores Associados Ltda., v. 112, jul. 1988. Mensal. ISSN 0101-1766

PROJETO: Arquitetura, planejamento, desenho industrial, construção. São Paulo: Projeto Editores Associados Ltda., v. 114, set. 1988. Mensal. ISSN 0101-1766

PROJETO: Arquitetura, planejamento, desenho industrial, construçáo. São Paulo: Projeto Editores Associados Ltda., v. 117, dez. 1988. Mensal. ISSN 0101-1766

PROJETO: Arquitetura, planejamento, desenho industrial, construçáo. São Paulo: Projeto Editores Associados Ltda., v. 118, jan./fev. 1989. Mensal. ISSN 0101-1766

PROJETO: Arquitetura, planejamento, desenho industrial, construçáo. São Paulo: Projeto Editores Associados Ltda., v. 122, jun. 1989. Mensal. ISSN 0101-1766

PROJETO: Arquitetura, planejamento, desenho industrial, construçáo. São Paulo: Projeto Editores Associados Ltda., v. 128, dez. 1989. Mensal. ISSN 0101-1766

PROJETO: Arquitetura, planejamento, desenho industrial, construçáo. São Paulo: Projeto Editores Associados Ltda., v. 133, set. 1990. Mensal. ISSN 0101-1766

PROJETO: Arquitetura, planejamento, desenho industrial, construçáo. São Paulo: Projeto Editores Associados Ltda., v. 134, jun. 1990. Mensal. ISSN 0101-1766

PROJETO: Arquitetura, planejamento, desenho industrial, construçáo. São Paulo: Projeto Editores Associados Ltda., v. 137, dez. 1990 / jan. 1991. Mensal. ISSN 0101-1766

RAGO, Margareth. A Colonização da Mulher. In: RAGO, Margareth. Do cabaré ao lar: a utopia da cidade disciplinar. 2. ed. Rio de Janeiro: Paz e Terra, 1985. Cap. 2. p. 61-95.

RIBEIRO, Djamila. O que é lugar de fala? Belo Horizonte: Letramento, 2017. 96 p.

SÔNIA MARQUES (São Paulo). Arquitetura brasileira: uma Pós-Modernidade mais do que contraditória. Rua Revista, Campinas, v. 5, n. 1, p.82-95, 1999. Disponível em: <https://portalseer.ufba.br/index.php/ rua/article/view/3138>. Acesso em: 29 ago. 2019. 
WAISMAN, Marina. La mujer en la arquitectura. Revista de La Universidad Nacional de Córdoba, Ciudad Universitaria, v. 1 e 2, n. , p.379-393, mar./jun. 1969. Bimestral. Disponível em: <https://undiaunaarquitecta.files.wordpress.com/2015/05/marina-waisman-la-mujer-en-la-arquitectura_031.pdf>. Acesso em: 24 set. 2019.

ZEIN, Ruth Verde. YES, NÓS TEMOS CRÍTICA! 2008. Disponível em: <https://www.arcoweb.com.br/ projetodesign/artigos/artigo-yes-nos-temos-critica-01-05-2002>. Acesso em: 18 set. 2019. 